http://jmscr.igmpublication.org/home/ ISSN (e)-2347-176x ISSN (p) 2455-0450

crossref DOI: https://dx.doi.org/10.18535/jmscr/v8i9.04

Journal Of Medical Science And Clinical Research

\title{
Functional Outcome of Uncemented Modular Bipolar Hemiarthroplasty Using Modified Harris Hip Score for Fractures of Femoral Neck in Elderly Patients
}

Authors

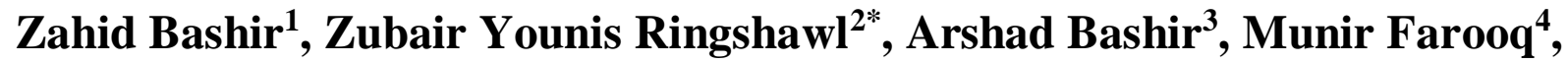 Mubashir Maqbool Wani ${ }^{5}$}

${ }^{1}$ MBBS, MS (Anatomy), Post Graduate Scholar, Deptt. of Orthopaedics, Government Medical College, Srinagar

${ }^{2}$ MBBS, Post Graduate Scholar, Deptt. of Orthopaedics, Government Medical College, Srinagar.

${ }^{3}$ MBBS, MS(Ortho), Associate Professor, Deptt. of Orthopaedics, Government Medical College, Srinagar.

${ }^{4}$ MBBS, MS (Ortho), Professor and Head, Deptt. of Orthopaedics, Government Medical College, Srinagar.

${ }^{5}$ MBBS, MS (Ortho), Lecturer, Deptt. of Orthopaedics, Government Medical College, Srinagar.

*Corresponding Author

\section{Zubair Younis Ringshawl}

\begin{abstract}
Introduction: Fractures of neck of femur are commonly seen in elderly people although all age groups can be affected, but increased predilection is seen in osteoporotic bones. The results of internal fixation are marked by a high incidence of nonunion and avascular necrosis. Several studies have found hemiarthroplasty to be better and more reliable than internal fixation in elderly patients. The introduction of modular hemiarthroplasty whether unipolar or bipolar was an advancement because the neck length can be adjusted with regards to tension of abductors and leg length and further it can more easily be converted to Total Hip Replacement.

Aims and Objectives: Evaluation of functional outcome of uncemented modular bipolar hemiarthroplasty using Modified Harris Hip Score for fractures of femoral neck in elderly patients.

Material and Methods: The present study was a hospital based prospective study done on patients admitted in the Post Graduate Department of Orthopedics, Government Hospital for Bone and Joint Surgery, an associated hospital of Government Medical College, Srinagar. A total of fifty patients were taken up for the study.

Results: The mean age was 72.4 years (range 61 - 88 years). There were 20 (40\%) male cases and 30 $(60 \%)$ female cases (sex ratio $=1: 1.5$ ). Minor domestic trauma and fall was the cause of injury in $90 \%$ of the patients. The mean pre-operative score was 32.93, the maximum score being 65 and the minimum being 16. Postoperatively the mean total score was 88.967, with 76 being the minimum and 100 being the maximum.

Conclusion: Hemiarthroplasty using Modular Uncemented Bipolar prosthesis for fractures of the displaced femoral neck in elderly provides pain relief, better range of movement and more rapid return to unassisted activity with an acceptable complication rate. Though conventionally done in a cemented fashion, uncemented modular hemiarthroplasty provides a good primary anchorage with equally promising results.
\end{abstract}




\section{Introduction}

Fractures of neck of femur are commonly seen in elderly people although all age groups can be affected, but increased predilection is seen in osteoporotic bones (Aitken, 1984) ${ }^{1}$.

The best treatment for the active and lucid elderly patient with displaced intra-capsular femoral neck fracture is still controversial and has been rightly called "Unsolved Fracture" by Dickson (1953) 2 . Over the years in spite of increase in knowledge about the epidemiology of this fracture, the biomechanics and vascular supply of the hip and proximal femur, no universally accepted treatment exists; and due to high energy road traffic accidents the fracture has presented in young patients with increased frequency further complicating the establishment of definitive treatment.

It was Whitman R (1902) ${ }^{3}$ who attempted the treatment of fracture neck of femur by immobilizing the fracture in a spica cast. About $1 / 3$ rd of the patients who survived the plaster complications showed union.

Later the emphasis turned towards the operative treatment i.e. internal fixation in many forms but the one that showed significance was the triflanged nail by Smith PMN $(1923)^{4}$ which made the internal fixation more acceptable because the fracture was reduced under direct vision. But the results of Internal Fixation were not very promising. Even in undisplaced fractures in octogenarians the re-operation rate was $31 \%$ (Hui et al) ${ }^{5}$.

The results of internal fixation are marked by a high incidence of nonunion and avascular necrosis.

Several studies have found hemiarthroplasty to be better and more reliable than internal fixation in elderly patients(Johnson and Crothers, 19756; Soreide O et al., 19797; Bray TJ et al., 1988 ${ }^{8}$; Pathi KM and Murthi BS, 1989 ${ }^{9}$ ) as it avoids many complications and second surgeries as compared to internal fixation.

Hemiarthroplasty has been considered as a safe operation in elderly as the operative time as well as postoperative rehabilitation is shorter and does not involve issues like vascularity of femoral head and fracture union.

Though short term results were good but long term results for conventional hemiarthroplasty for displaced subcapital fractures demonstrate that nearly $1 / 3^{\text {rd }}$ of the patients may suffer disability mainly due to acetabular erosion, implant sinking, loosening of the prosthesis and infection, more so in young and active individuals. Anderson and colleagues $(1964){ }^{10}$ showed a fracture rate of $4.5 \%$ while attempting to reduce hip after prosthetic replacement.

Bipolar prosthesis is a better alternative to conventional hemiarthroplasty and has been shown to have decreased incidence of acetabular protrusion compared with unipolar prosthesis (LaBelle LW et al, 1990) ${ }^{11}$; although the functional outcomes were same in both groups with regards to dislocation rate (Paton RW and Hirst P, 1989) ${ }^{12}$, bipolar provided a longer symptom free period than the Austin Moore (Kaltas DS and Klugman DJ, 1986) ${ }^{13}$.

The further advancement was introduction of modular hemiarthroplasty whether unipolar or bipolar. Most of the studies between modern modular or bipolar components vs Austin Moore or a Thompson's prosthesis show that the former are better because the neck length can be adjusted with regards to tension of abductors and leg length and further it can more easily be converted to Total Hip Replacement.

\section{Aims and Objectives}

Evaluation of functional outcome of uncemented modular bipolar hemiarthroplasty using Modified Harris Hip Score for fractures of femoral neck in elderly patients.

\section{Materials and Methods}

The present study was a hospital based prospective study done on patients admitted in the Post Graduate Department of Orthopedics, Government Hospital for Bone and Joint Surgery, an associated hospital of Government Medical 
College, Srinagar. A total of fifty patients were taken up for the study.

\section{Criteria for Selection of Patients Inclusion Criteria}

1) Age $>60$ years.

2) Garden's type III and type IV fractures.

3) Pre-injury independent walking capability with or without aids.

4) Both fresh and old fractures were included.

5) Nonunion of fracture neck femur.

6) Avascular necrosis of femoral head following prior treatment.

7) Implant failure.

8) Abbreviated Mental Test Score $\geq 6$.

9) Dorr Type A or Type B femur.

\section{Exclusion Criteria}

1) Un-displaced Fractures (Garden's type I and II).

2) Patients with pre-existing joint diseases like Rheumatoid arthritis, Osteoarthritis.

3) Patients with Pathological Fractures, Multiple fractures.

4) Pre-injury non-ambulatory patients.

5) Abbreviated Mental Test Score (AMTS) $<6$.

6) Patients with medical contraindications for surgery/anaesthesia.

7) Psychiatry patients with mental instability.

8) Dorr Type C femur.

\section{Pre-Operative Planning}

Detailed history with general physical examination was taken to rule out any systemic disorder. Any limb length discrepancy, range of motion (ROM) of the affected hip and any deformity, if present, was recorded and hip function was assessed as per the Modified Harris Hip Score (HHS).

Radiograph of the pelvis AP view with both hips and at least proximal $7 \mathrm{cms}$. of femur in addition to lateral view were done. The AP views were obtained with the patients lying supine on the table with the hips in 10-15 degrees on internal rotation. This allows a true AP view of the femoral neck. These x-rays were $20 \%$ magnified.

\section{Surgical Technique}

All patients received a single dose of prophylactic antibiotic (Cefuroxime, $1.5 \mathrm{gm}$ ) one hour before surgery. The patient was placed in the lateral decubitus position. An impervious plastic U-drape was placed to drape out the perineum. Foot and leg was draped with a large stockinette. Iodineimpregnated incision drape was then placed covering all exposed skin.

All surgeries were performed through the posterior (Moore) approach to hip. The incision was placed 8-10 cms distal to the Posterior Superior Iliac Spine (PSIS) and was extended distally and laterally parallel with the fibers of the gluteus maximus to the posterior margin of the greater trochanter. The deep fascia was divided in line with the skin incision. The fibers of the gluteus maximus were separated by blunt dissection taking care not to disturb the superior gluteal vessels in the proximal part of the incision. The sciatic nerve was exposed and was carefully retracted laterally. The gemelli, obturator internus and piriformis were exposed and divided at their insertion into femur. The posterior part of the joint capsule, which was now well visualized, was incised. The thigh and knee was flexed to 90 degrees. The thigh was rotated internally and the hip was dislocated posteriorly.

An osteotomy of the femoral neck with an oscillating power saw was done. The femoral head was removed from the wound by dividing any soft tissue attachments. The femoral canal was then prepared. A box chisel was used to remove the remaining lateral neck. The reamer was then inserted and directed towards the medial femoral condyle. The femoral canal was then progressively broached to the proper size. The final broach was seated to a point where it becomes stable and did not advance further. A trial stem was inserted using stem impactor. Chosen trial head was fixed onto trial prosthesis and reduction done. 
The hip was considered stable if no dislocation occurred (1) in full extension with 40 degrees of external rotation, (2) in flexion to 90 degrees with at least 45 degrees of internal rotation, and (3) with the hip flexed 40 degrees with adduction and axial loading (the so called position of sleep). If the hip dislocated easily of if more than half the femoral head could be manually distracted from the socket with direct axial traction (the so-called shuck test), a longer neck length was used. The trial components were removed. The appropriate sized femoral component was inserted in the precise degree of anteversionas determined by the broach. The prosthetic head of appropriate size and neck length were placed onto the stem, and fixed again with a few blows of a mallet over a plastic capped head impactor. The hip was again reduced and stability was assessed by moving the hip through a functional range of motion.

The wound was closed in layers, over a suction drain and an abduction splint was applied on table. Patients were then shifted to postoperative ward, with an abduction bar between the thighs and were instructed not to flex, adduct and internally rotate the operated limb. Deep vein thrombosis (DVT) prophylaxis using Enoxaparin $40 \mathrm{mg}$ injected subcutaneously, once a day, starting on the day after surgery was given to patients for 14 days. Oral Aspirin $325 \mathrm{mg}$ once daily (reducible till $75 \mathrm{mg}$ OD) was given for 4 weeks after discontinuation of low molecular weight heparin.

Postoperative radiographs were evaluated for component orientation, limb length discrepancy and femoral stem orientation. Physical therapy program consisting of deep breathing, coughing and bilateral active ankle exercise and isometric contraction of the quadriceps muscles were started from first postoperative day.

Post-operative follow up was done at 2, 6, 12 weeks, 6 months and final follow up at 1 year both clinically and radiologically. Final assessment of all patients was done by modified Harris Hip Scoring system (William H Harris, 1969).

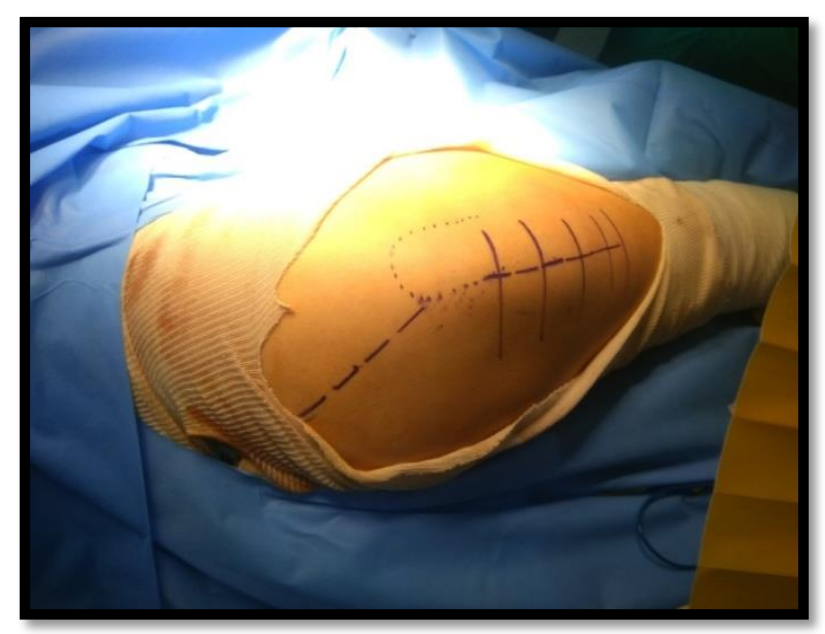

Marking of the Skin Incision

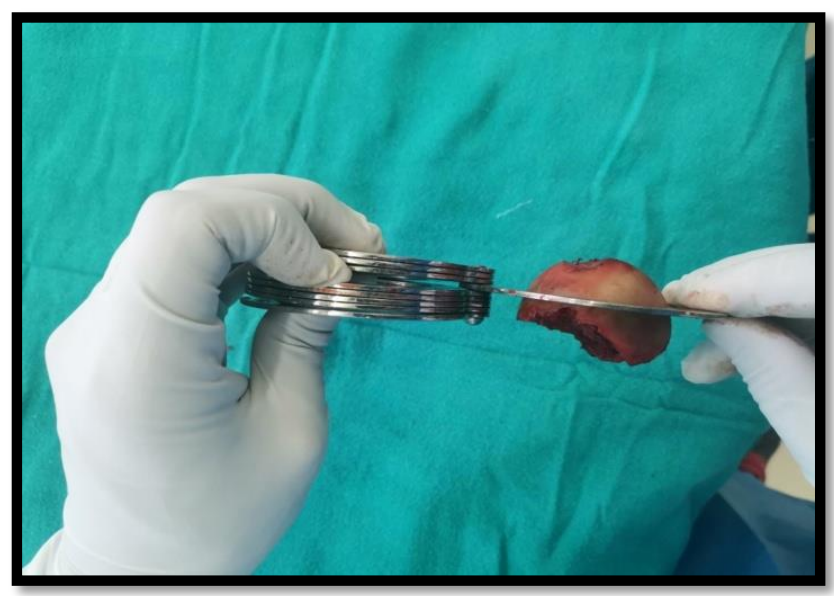

Measuring the size of the femoral head using Murphy's guage

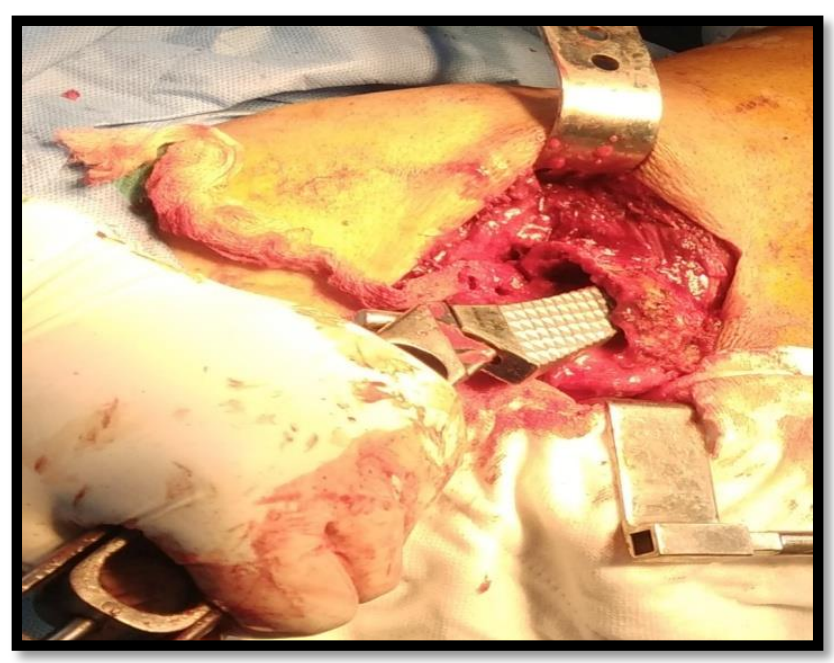

Insertion of the Trial Femoral Stem 


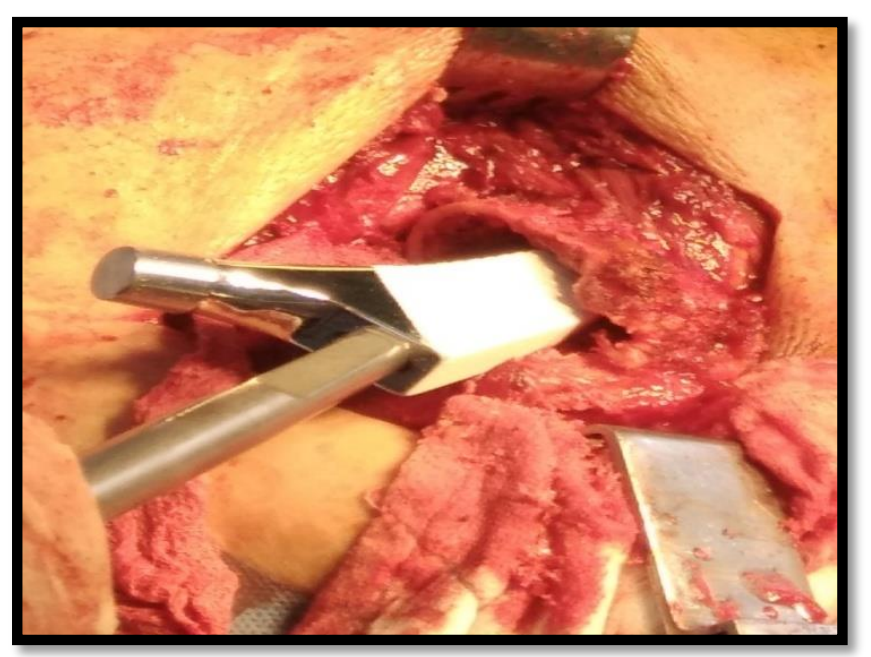

Insertion of final Femoral stem

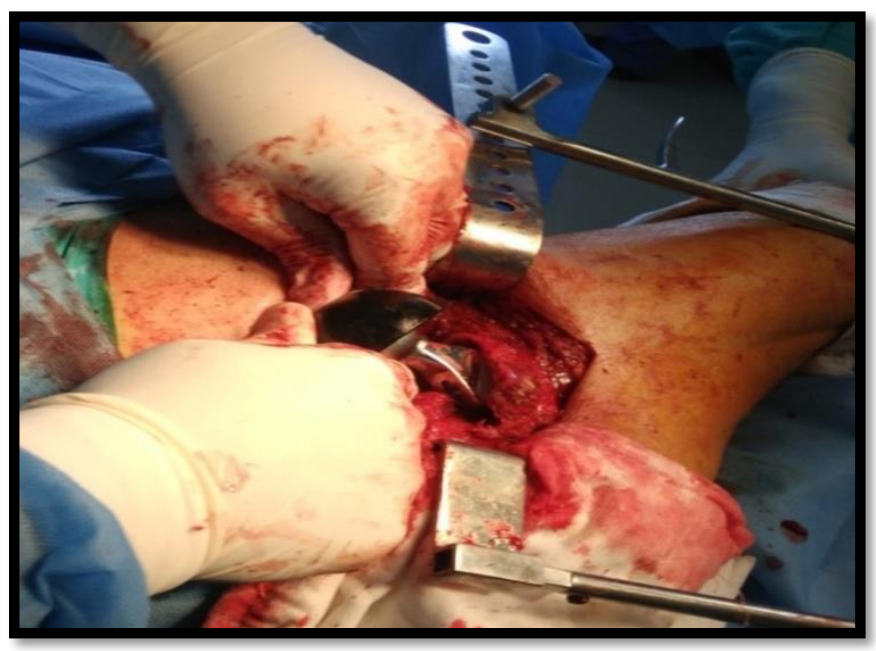

Using Trial head

\section{Results}

All patients were more than 60 years old. The mean age was 72.4 years (range 61 - 88 years). There were $20(40 \%)$ male cases and $30(60 \%)$ female cases $($ sex ratio $=1: 1.5)$. The left side $(53.33 \%)$ was involved more than right side (46.67\%). There were 18 (60\%) Garden type IV fractures and 12 (40\%) Garden type Ill fractures.

Minor domestic trauma and fall was the cause of injury in $90 \%$ of the patients. All patients were preoperatively mobile, independently enjoying unrestricted activity. The mean interval between the injury and operation was 9.73 days (range 5 17days). The average blood loss was $256.33 \mathrm{ml}$ (range 150- $450 \mathrm{ml}$ ). The average duration of surgery was $130.6 \mathrm{~min}$ (range 90-120 $\mathrm{min}$ ).
$83.33 \%$ patients were pain free and were enjoying independent mobility at last follow up.

The mean femoral head diameter was $47.23 \mathrm{~mm}$ (range 43- $53 \mathrm{~mm}$ ). Most commonly used femoral stem size was medium plus.

The mean range of motion score was 4.12 (range 3-5). The mean functional score achieved was 34.63(25 -43). Excellent results were obtained in $6.67 \%$.Good results were obtained in $70 \%$ patients. Fair result was obtained in $16.66 \%$ patients.

No femoral component loosening / migrations were noticed. Dislocation did not occur in any patient. There were no fixed hip deformities in any patient.

The average duration of hospital stay was 13.7days (range 10-17 days). None of the patient developed deep infection. The average period of follow up was 8.63 months (range 6 - 11 months)

The mean pre-operative score was 32.93 , the maximum score being 65 and the minimum being 16. Postoperatively the mean total score was 88.967, with 76 being the minimum and 100 being the maximum.

The complications included hypotension, superficial infection, pressure sores, periprosthetic fracture, Limb length Discrepancy, Persistent Anterior Thigh Pain.

\section{Discussion}

Considering higher rates of nonunion (Skinner $\mathbf{P}$ et al, 1986) ${ }^{\mathbf{1 4}}$, avascular necrosis (Barnes $\mathbf{R}$, 1976) ${ }^{\mathbf{1 5}}$ and revision rates (Parker MJ, 1992) ${ }^{\mathbf{1 6}}$ following internal fixation, arthroplasty is emerging as the treatment of choice in the elderly patients with intracapsular fracture neck of femur. Age incidence: $30 \%$ of the patients were in the age group of $60-70$ years and $60 \%$ in age group of 70 - 80 years. There were 5 patients in age group of 80 - 90 years. The mean age was 72.4 years. The range of age was 61 - 88 years. The mean age is comparable with study of Thompson $R$ et al (2004) ${ }^{17}$, Jasty $M$ et al $(\mathbf{2 0 0 1})^{18}$ and Nottage WM et al (1990) ${ }^{19}$. 


\begin{tabular}{|l|c|c|c|c|}
\hline Study & $\begin{array}{c}\text { Thompson } \\
\text { R et al } \\
\mathbf{( 2 0 0 4 )}^{\mathbf{1 7}}\end{array}$ & $\begin{array}{c}\text { JastyM } \\
\text { et al } \\
\mathbf{( 2 0 0 1 )}^{\mathbf{1 8}}\end{array}$ & $\begin{array}{c}\text { NottageWM } \\
\text { et al } \\
\mathbf{( 1 9 9 0 )}^{\mathbf{1 9}}\end{array}$ & $\begin{array}{c}\text { Present } \\
\text { study }\end{array}$ \\
\hline $\begin{array}{l}\text { Mean } \\
\begin{array}{l}\text { Age } \\
\text { (Years) }\end{array}\end{array}$ & 80.8 & 76.4 & 70.8 & 72.4 \\
\hline
\end{tabular}

Sex Distribution: There were 20 (40\%) male patients and $30(60 \%)$ female patients (sex ratio 1:1.5). This shows that the incidence of fracture neck femur is more in female group. This is comparable to sex ratio of most of the studies in which the incidence has been shown to be more in females (Archibeck JM et al., 196920; Moshein J et al., 1990 ${ }^{21}$; Pearse MF et al, 1992) ${ }^{22}$.

\begin{tabular}{|l|c|c|c|c|}
\hline Study & $\begin{array}{c}\text { Archibeck } \\
\text { JM et al } \\
(\mathbf{1 9 6 9})^{\mathbf{2 0}}\end{array}$ & $\begin{array}{c}\text { MosheinJ } \\
\text { et al } \\
(\mathbf{1 9 9 0})^{\mathbf{2 1}}\end{array}$ & $\begin{array}{c}\text { Pearse MF } \\
\text { et al } \\
\mathbf{( 1 9 9 2 )}^{\mathbf{2 2}}\end{array}$ & $\begin{array}{c}\text { Present } \\
\text { study }\end{array}$ \\
\hline Sex Ratio & $1: 1.8$ & $1: 1.7$ & $1: 2$ & $1: 1.5$ \\
\hline
\end{tabular}

Type of Fracture: There were 30 (60\%) Garden's type IV fractures and 20 (40\%) Garden's type III fractures. Ratio of Garden's type Ill to type IV was $1: 1.35$. This is to some extent in accordance with observations made by other studies Askin SR et al. $(1976)^{23},(1: 2)$ and Greenough and Jones $(1: 2)^{24}$.

\begin{tabular}{|l|c|c|c|}
\hline Study & $\begin{array}{c}\text { Askin SR et } \\
\text { al (1976) }\end{array}$ & $\begin{array}{c}\text { Greenough } \\
\text { CG et al } \\
(\mathbf{1 9 8 8})^{\mathbf{2 4}}\end{array}$ & $\begin{array}{c}\text { Present } \\
\text { Study }\end{array}$ \\
\hline $\begin{array}{l}\text { Ratio (Garden } \\
\text { Type 3:Type 4) }\end{array}$ & $1: 2$ & $1: 2$ & $1: 1.35$ \\
\hline
\end{tabular}

\section{Stem Alignment}

\begin{tabular}{|l|c|c|c|}
\hline Study & $\begin{array}{c}\text { Nottage } \\
\text { WM et al } \\
(\mathbf{1 9 9 0})^{\mathbf{1 9}}\end{array}$ & $\begin{array}{c}\text { Bloomfeld R } \\
\text { et al (2007) }\end{array}$ & $\begin{array}{c}\text { Present } \\
\text { study }\end{array}$ \\
\hline $\begin{array}{l}\text { Varus } \\
\text { alignment }\end{array}$ & $8 \%$ & $4 \%$ & $5.7 \%$ \\
\hline $\begin{array}{l}\text { Valgus } \\
\text { alignment }\end{array}$ & $22 \%$ & $11 \%$ & $9.9 \%$ \\
\hline $\begin{array}{l}\text { Central } \\
\text { alignment }\end{array}$ & $\mathbf{7 0 \%}$ & $85 \%$ & $84.4 \%$ \\
\hline
\end{tabular}

Duration of Hospital Stay: The average duration of hospital stay (from admission till the patient was discharged) was 13.7days (range 10-17 days). This is in accordance with the studies of Calder SJ et al (1996) ${ }^{26}$, Bloomfeld $R$ et al., (2007) ${ }^{25}$.

\begin{tabular}{|l|c|c|c|}
\hline Study & $\begin{array}{c}\text { Calder } \\
\text { SJ et al } \\
\mathbf{( 1 9 9 6 )}^{\mathbf{2 6}},\end{array}$ & $\begin{array}{c}\text { Bloomfeld } \\
\text { R et al } \\
\mathbf{( 2 0 0 7 )}^{\mathbf{2 5}}\end{array}$ & $\begin{array}{c}\text { Present } \\
\text { study }\end{array}$ \\
\hline $\begin{array}{l}\text { Duration of hospital } \\
\text { stay (Days) }\end{array}$ & 10.8 & 11.4 & 13.7 \\
\hline
\end{tabular}

Blood Loss: The average blood loss was 256.33 $\mathrm{ml}$ (range $150-450 \mathrm{ml}$ ). These findings are comparable to the findings of Blomfeld $\mathbf{R}$ et al., $(2007)^{25}$.

Hip Score Grading: The hip score grading was done on the basis of modified Harris Hip Score which includes evaluation of pain, function and physical examination.

Pain: 12 patients (23.33\%) had no pain, 30 (60\%) patients had slight or intermittent pain. Thus 42 patients $(83.33 \%)$ had no or minimal pain. 8 patients $(16.67 \%)$ had mild pain. None of the patients had moderate, marked or severe pain. None of the patients was totally disabled in terms of pain. The average pain score was 39.26 (range 30-44). The results are comparable to other studies.

\section{Comparison of Pain Grading:}

\begin{tabular}{|l|c|}
\hline Author & No or slight pain (percent) \\
\hline Long JW et al (1980) $)^{\mathbf{2 7}}$ & 97 \\
\hline Bochner RMet al.(1988) & 91 \\
\hline Pearse MF et al (1992) & 94 \\
\hline Present study & 83.33 \\
\hline
\end{tabular}

Function: The mean functional score achieved was 34.63 (25 - 43). Most of the patients were capable of doing their normal activities and were independently mobile without any walking aid. 8 patients $(16.66 \%)$ had excellent functional score. 2 patients (4\%) used cane for support during walking preoperatively and continued to use it afterwards also.

Range of Motion: 10 patients achieved excellent range of motion (sum of flexion, abduction, adduction, external rotation and internal rotation $>210$ degrees).

Total Hip Score. The average Modified Harris Hip Score was 81.26(range 69-91). The Modified Harris Hip Score was comparable to other studies:

\begin{tabular}{|l|c|}
\hline Author & Mean Harris Hip Score \\
\hline La-Belle LW et al (1990) $^{\mathbf{1 1}}$ & 80 \\
\hline Lestrange NR (1990) $^{\mathbf{2 9}}$ & 82.6 \\
\hline Moshein J et al. (1990) $^{\mathbf{3 0}}$ & 82.4 \\
\hline NottageWM et al (1990) $^{\mathbf{1 9}}$ & 82.4 \\
\hline Narayan KK et al (2006) $^{\mathbf{3 1}}$ & 86.93 \\
\hline Present study & 81.26 \\
\hline
\end{tabular}




\section{Conclusion}

Hemiarthroplasty using Modular Uncemented Bipolar prosthesis for fractures of the displaced femoral neck in elderly provides pain relief, better range of movement and more rapid return to unassisted activity with an acceptable complication rate. Though conventionally done in a cemented fashion, uncemented modular hemiarthroplasty provides a good primary anchorage with equally promising results.

The end functional results also depend on the associated co-morbidity and optimum postoperative rehabilitation. Throughout the purview of the present study, our experience with Uncemented Modular bipolar prosthesis has been better. The long term results using Modular Uncementedbipolar prosthesis needs further study. The short term outcome from this study provides evidence that this is suitable treatment option in displaced intracapsular fracture neck of femur in elderly.

\section{References}

1. Aitken JM. Relevance of osteoporosis in women with fracture of femoral neck. $B M J$ 1984; 288:597-60.

2. Dickson JA. The unsolved fracture. $J$ Bone Joint Surg 1984;35-A:805-822.

3. Whitman R.A new method of treatment for fractures of neck femur together with remarks on coxavara. Ann Surg1902; 36:746-761.

4. Smith Peterson MN, Cave EF, Vangorder GW. Intracapsular fractures of neck femur. Archives of Surgery1931; 23:715.

5. Hui AC, Anderson GH,C houdhry $R$. Internal fixation or hemiarthroplasty for undisplaced fractures of femoral neck in octogenarians. J Bone Joint Surg1994; 76:891-894.

6. Johnson JTH, Crothers O. Nailing versus prosthesis for femoral neck fracture. J Bone Joint Surg1975; 57-A: 686-692
7. Soreide O, Molster A, Raugstad TS. Internal fixation versus primary prosthetic replacement in acute femoral neck fractures: a prospective, randomized clinical study. Br J Surg 1979; 66:56-60.

8. Bray TJ, Smith Hoefer E and Hooper A et al. The displaced femoral neck fracture: internal fixation versus bipolar endoprosthesis: results of a prospective, randomized comparison. Clin Orthop 1988; 230:127-140.

9. Pathi KM, Murthy BS. Hemiarthroplasty versus internal fixation for displaced subcapital fracture neck femur. Indian Journal of Orthropaedics1989; 23:149151.

10. Anderson LD, Hamsa WR, Warling TL. Femoral head prosthesis.J Bone Joint Surg 1964; 46:1049-1065.

11. La Belle LW, Collwill JC, Swanson AB. Bateman bipolar hip arthroplasty for femoral neck fractures.Clin Orthop1990; 251:20-25.

12. Paton RW, Hirst P. Hemiarthroplasty of hip and dislocations. Injury 1989; 20(3): 167-169.

13. Kaltas DS, Klugman DJ. Acetabular erosion: A comparison between Austin Moore and Monk hard top prosthesis. Injury 1986; 17:4:230-236.

14. Skinner P, Riley D and Ellery Jet al. Displaced subcapital fractures of femur: Aprospective randomized comparison of internal fixation, hemiarthroplasty and total hip replacement. Injury1989;20:291293.

15. Barnes R, Brown JT and Garden RS et al. Subcapital fractures of femur. A prospective review. J Bone Joint Surg Br1976; 58(1):2-24.

16. Parker MJ, Pryor GA and Anand JK et al. A comparison of presenting characteristics of patients with intracapsular and extracapsular proximal 
femoral fractures. Journal of Royal Society of Medicine 1992; 85:152-155.

17. Thompson R, Lovett. R. W; Primary cementless hemiarthroplasty hip in octogenarians. Two-Eleven year followup. J Bone Joint Surgery Br 200432 B; 166-173.

18. Jasty M, Engh C, Harris W. Apreliminary report $\mathrm{f}$ femoral neck fractures as function of age. A prospective study. J Bone Joint Surgery Br. 2001; 87 B; 155-7.

19. Nottage WM, McMaster WC. Comparison of bipolar implants with fixed-necked prosthesis in femoral neck fractures. ClinOrthop 1990; 251:38-44.

20. Archibeck M. J., Corten k., Bowerman J.: Factors affecting bone mineral density around the femoral stem after hip hemiarthroplasty. Chir Narzadow Ruchu Orthop Pol.1969; 64 (4); 415-21.

21. Moshein J, Alter AH and Elconin KB et al. Transcervical fractures of hip treated with Bateman bipolar prosthesis. ClinOrthop 1990; 251:48-53.

22. Pearse MF, Bande $\mathbf{S}$ and $\mathbf{O}$ Dwyer et al. The Exeter bipolar prosthesis in active elderly patients: the result at 7 years. IntOrthop 1992; 16(4):344-348.

23. Askin SR, Bryan RS. Femoral neck fractures in young adults. ClinOrthop 1976; 114:259-264.

24. Greenough CG, Jones JR. Primary total hip replacement for displaced subcapital fracture of the femur. J Bone Joint Surg [Br] 1988;70B:639-643.

25. Blomfeldt R, Tornkvist and Eriksson $\mathbf{K}$ et al. A randomised controlled trial comparing bipolar hemiarthroplasty with total hip replacement for displaced intracapsular fractures of femoral neck in elderly patients. J Bone Joint Surg 2007; 89-B (2):160-165.
26. Calder J. Evolution of hip hemiarthroplasty. Ann chirGynaecol. 1996; 71: 103.

27. Long JW and Knight W. Bateman UPF prosthesis in fractures of femoral neck. Clin Orthop. 1980; 152:198-201.

28. Bochner RM, Pellici PM, Lyden JP. Bipolar hemiarthrsoplasty for fractures of femoral neck. J Bone Joint Surgery [AM] 1988;70: 1001-1010.

29. Lestrange NR. Bipolar arthroplasty for 496 hip fractures. ClinOrthop.1990; 251:719.

30. Moshein J, Alter AH and Elconin KB et al. Transcervical fractures of hip treated with Bateman bipolar prosthesis. Clin Orthop 1990; 251:48-53.

31. Narayan KK, George T. Functional outcome of fracture neck of femur treated with total hip replacement versus bipolar arthroplasty in a south Asian population (J). Arch Orthop Trauma Surg2006; 126(8):545-548. 